November 2003 - NREL/CP-500-34979

\title{
Methods for Increasing Region 2 Power Capture on a Variable Speed HAWT
}

\section{Preprint}

K.E. Johnson and L.J. Fingersh

National Renewable Energy Laboratory

M.J. Balas and L.Y. Pao

University of Colorado

To be presented at the $23^{\text {rd }}$ ASME Wind Energy

Symposium

Reno, Nevada

January 5-8, 2004

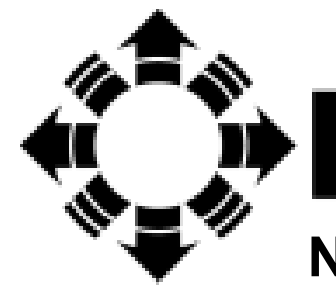

\section{NPEI}

National Renewable Energy Laboratory

1617 Cole Boulevard

Golden, Colorado 80401-3393

NREL is a U.S. Department of Energy Laboratory

Operated by Midwest Research Institute $\bullet$ Battelle $\bullet$ Bechtel

Contract No. DE-AC36-99-G010337 


\section{NOTICE}

The submitted manuscript has been offered by an employee of the Midwest Research Institute (MRI), a contractor of the US Government under Contract No. DE-AC36-99G010337. Accordingly, the US Government and MRI retain a nonexclusive royalty-free license to publish or reproduce the published form of this contribution, or allow others to do so, for US Government purposes.

This report was prepared as an account of work sponsored by an agency of the United States government. Neither the United States government nor any agency thereof, nor any of their employees, makes any warranty, express or implied, or assumes any legal liability or responsibility for the accuracy, completeness, or usefulness of any information, apparatus, product, or process disclosed, or represents that its use would not infringe privately owned rights. Reference herein to any specific commercial product, process, or service by trade name, trademark, manufacturer, or otherwise does not necessarily constitute or imply its endorsement, recommendation, or favoring by the United States government or any agency thereof. The views and opinions of authors expressed herein do not necessarily state or reflect those of the United States government or any agency thereof.

Available electronically at http://www.osti.gov/bridge

Available for a processing fee to U.S. Department of Energy and its contractors, in paper, from:

U.S. Department of Energy

Office of Scientific and Technical Information

P.O. Box 62

Oak Ridge, TN 37831-0062

phone: 865.576.8401

fax: 865.576.5728

email: reports@adonis.osti.gov

Available for sale to the public, in paper, from:

U.S. Department of Commerce

National Technical Information Service

5285 Port Royal Road

Springfield, VA 22161

phone: 800.553 .6847

fax: 703.605.6900

email: orders@ntis.fedworld.gov

online ordering: http://www.ntis.gov/ordering.htm

Printed on paper containing at least $50 \%$ wastepaper, including $20 \%$ postconsumer waste 


\title{
METHODS FOR INCREASING REGION 2 POWER CAPTURE ON A VARIABLE SPEED HAWT
}

\author{
K. E. Johnson and L. J. Fingersh \\ National Renewable Energy Laboratory, MS 3811, 1617 Cole Boulevard, Golden, Colorado 80401-3393 \\ kathryn_johnson@nrel.gov, lee_fingersh@nrel.gov
M. J. Balas, Aerospace Engineering, and L. Y. Pao, Electrical Engineering
University of Colorado, Boulder, Colorado 80309
mark.balas@colorado.edu, pao@colorado.edu

\begin{abstract}
The standard region 2 control scheme for a variable speed wind turbine, $\tau_{c}=k \omega^{2}$, has several shortcomings that can result in significant power loss. The first of these is that there is no accurate way to determine the gain $k$; modeling programs are not accurate enough to represent all of the complex aerodynamics, and these aerodynamics change over time. Furthermore, it is not certain whether the value of $k$ used in the standard control even provides for the maximum energy capture under real-world turbulent conditions. New control ideas are introduced to address these issues. First, it is shown in simulation that using smaller values of $k$ than the standard can result in increased power capture. Second, an optimally tracking rotor control scheme improves upon the standard scheme by assisting the rotor speed in tracking wind speed fluctuations more rapidly. Finally, an adpative control scheme is proposed that allows for maximum power capture despite parameter uncertainty.
\end{abstract}

\section{NOMENCLATURE}

$\omega \quad$ rotor angular speed $(\mathrm{rad} / \mathrm{s})$

$v \quad$ wind speed $(\mathrm{m} / \mathrm{s})$

$\rho \quad$ air density $\left(\mathrm{kg} / \mathrm{m}^{3}\right)$

$A \quad$ rotor swept area $\left(\mathrm{m}^{2}\right)$

$R \quad$ rotor radius $(\mathrm{m})$

$J \quad$ rotor inertia $\left(\mathrm{kgm}^{2}\right)$

$C_{q} \quad$ rotor torque coefficient

$C_{p} \quad$ rotor power coefficient

$C_{p_{\max }}$ maximum rotor power coefficient

$\lambda_{*} \quad$ tip speed ratio (TSR) corresponding to $C_{p_{\max }}$

$P \quad$ rotor power $(\mathrm{kW})$

$P_{\text {cap }} \quad$ captured power $(\mathrm{kW})$

$P_{\text {wind }} \quad$ power available in the wind $(\mathrm{kW})$

$P_{w y} \quad$ power available in the wind, with approximate yaw error factor included $(\mathrm{kW})$

$P_{\text {frac }} \quad$ turbine captured power divided by wind power $(\mathrm{kW})$

$P_{\text {favg }} \quad$ average captured power divided by average wind power over a given time period $(\mathrm{kW})$

$\tau_{\text {aero }} \quad$ aerodynamic torque $(\mathrm{Nm})$

$\begin{array}{ll}\tau_{c} & \text { generator (control) torque }(\mathrm{Nm}) \\ \beta & \text { blade pitch (degrees) } \\ \psi & \text { yaw error (degrees) } \\ M & \text { adaptive gain }\left(\mathrm{m}^{5} / \mathrm{rad}^{3}\right) \\ n & \text { number of steps in adaptation period } \\ K_{\Delta M} & \text { positive gain on adaptation law }\left(\mathrm{rad}^{3} / \mathrm{m}^{5}\right)\end{array}$

\section{INTRODUCTION}

Variable speed wind turbines have three main regions of operation. The first, region 1 , includes the time when the turbine is starting up. Region 2 is an operational mode during which it is desirable that the turbine capture as much power as possible from the wind. Region 3 is encountered when the wind speeds are high enough that the turbine must limit the fraction of the wind power captured so that safe electrical and mechanical loads are not exceeded. This paper focuses on region 2 operation, which accounts for more than $50 \%$ of yearly energy capture for a typical modern turbine.

The standard region 2 control scheme for a variable speed wind turbine is given in Eq. (1)-(2).

$\tau_{c}=k \omega^{2}$

$k=\frac{1}{2} \rho A R^{3} \frac{C_{p \max }}{\lambda_{*}^{3}}$

where $\lambda_{*}$ is the optimal tip speed ratio, and tip speed ratio is defined as

$\lambda=\frac{\omega R}{v}$.

The control law in Eq. (1) is intended to keep the turbine operating at the peak of its $C_{p}$-TSR-Pitch surface. Figure 1 is an example of this surface, created using the modeling software PROP [1] for the Controls Advanced Research Turbine (CART). PROP conducts its simulations using blade-element-momentum theory (see, e.g., [2]). It should be noted that $C_{p}$ can be negative, as shown in Figure 1; negative $C_{p}$ corresponds to motoring operation when the turbine behaves like a fan, putting energy back into the wind. The CART is a $600 \mathrm{~kW}$, two-bladed, upwind turbine at the National Renewable Energy Laboratory's National Wind Technology Center (NWTC) and is the turbine test bed used in this research and for testing other advanced 
control algorithms. It is equipped with many more sensors than would be found on a commercial turbine, including a meteorological (met) tower about two rotor diameters away. This met tower is equipped with many weather-related sensors, including anemometers at hub height and at the heights of the blade tips when the rotor is oriented vertically. Figure 2 shows a photo of the CART, with the met tower on the left.

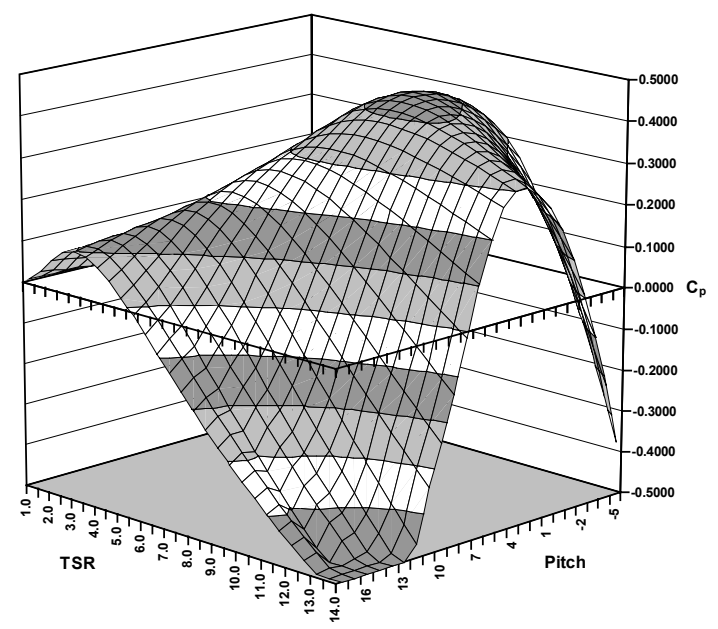

Figure 1: $C_{p}$ vs. TSR and Pitch for Controls Advanced Research Turbine (CART)

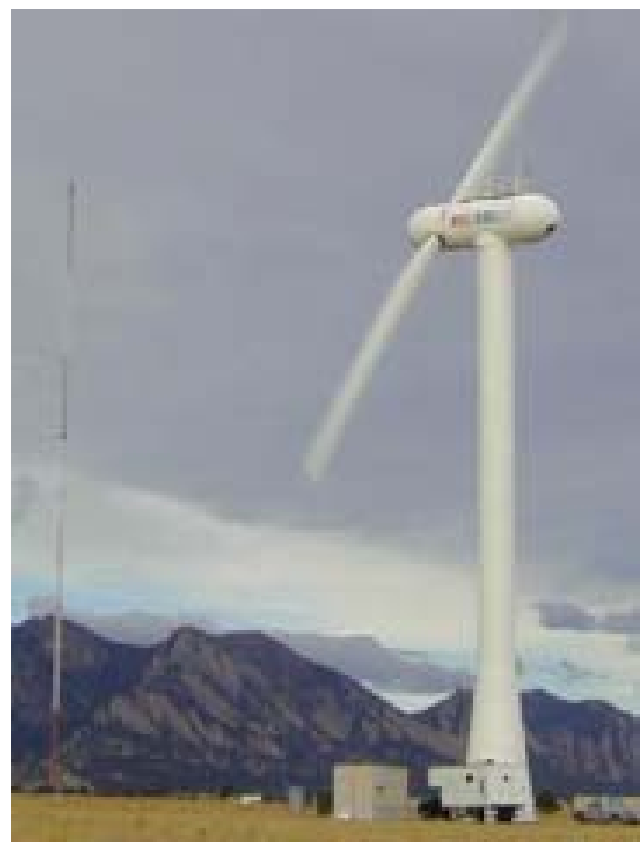

Figure 2: CART at the NWTC

The power coefficient is defined as the ratio of the turbine power to the power available in the wind:

$$
C_{p}=\frac{P}{P_{\text {wind }}},
$$

$P_{\text {wind }}=\frac{1}{2} \rho A v^{3}$.

From Eq. (4), it can be seen that rotor power is directly proportional to $C_{p}$; thus, operation at $C_{p_{\max }}$ is clearly desirable. The rotor power $P$ can be defined in different ways, which can result in slightly different interpretations of $C_{p}$; however, the most common definition of $P$ is

$P=\tau_{\text {aero }} \omega$

There are two significant problems with this standard control. The first is that there is no accurate way to determine $k$, especially since blade aerodynamics can change significantly over time. Second, even when it is assumed that $k$ can be accurately determined via simulation or experiments, wind speed fluctuations force the turbine to operate off the peak of its $C_{p}-\lambda$ curve much of the time, resulting in less energy capture. This paper addresses these issues in the following three ways:

First, the authors perform simulations to address the question of whether the $k$ used in the standard control actually results in optimum power capture for all wind conditions. These simulations indicate that, for a steady wind, this $k$ does indeed result in the optimum power capture. However, each increase in wind turbulence results in a corresponding decrease in the optimal operating point of the standard control law gain $k$, especially for turbines with large rotational inertias.

Next, the optimally tracking rotor (OTR) controller, which was originally proposed by Fingersh and Carlin [3], is examined in simulation. This control scheme reduces the amount of time the turbine requires to regain its optimal tip-speed-ratio by using generator torque to assist in acceleration or deceleration in response to wind gusts. Simulations are used to verify the effectiveness of OTR control; real data has been collected, as well, and is discussed in [4]. Optimally tracking rotor control assumes that the $k$ used in Eq. (1) is accurate and based on the peak of the $C_{p}-\lambda$ curve.

Finally, an adaptive controller is proposed that reduces the negative effects of both the uncertainty regarding $k$ and the change in optimal operating point due to turbulence. The adaptive controller will seek the gain that maximizes power capture, on average, regardless of whether this gain corresponds to the maximum of the $C_{p}-\lambda$ curve for the turbine. Both simulations and real data are used to verify the effectiveness of the adaptive controller.

Before the new control ideas are presented, however, an examination of the shortcomings of the existing torque control law is in order.

where 


\section{STANDARD CONTROL}

An understanding of how the standard torque control law given by Eq. (1) causes operation to occur, on average, at the optimum tip speed ratio (assuming the $C_{p}-\lambda$ curve is known exactly) will be useful in understanding the results in this paper. To study the dynamics of the system, consider a simple rigid body model of a wind turbine. The equation relating net torque and angular acceleration is

$\dot{\omega}=\frac{1}{J}\left(\tau_{\text {aero }}-\tau_{c}\right)$

where

$\tau_{\text {aero }}=\frac{1}{2} \rho A R C_{q}(\lambda, \beta) v^{2}$

and

$C_{q}(\lambda, \beta)=\frac{C_{p}(\lambda, \beta)}{\lambda}$.

While very simple, this rigid body model is a fair approximation for the CART, which has a very rigid rotor. Now, substitute Eq. (8) and Eq. (1) into Eq. (7):

$\dot{\omega}=\frac{1}{J}\left(\frac{1}{2} \rho A R C_{q}(\lambda, \beta) v^{2}-\frac{1}{2} \rho A R^{3} \frac{C_{p \max }}{\lambda_{*}{ }^{3}} \omega^{2}\right)$.

Then, simplify Eq. (10) further with Eq. (9) and Eq. (3):

$\dot{\omega}=\frac{1}{2 J} \rho A R^{3} \omega^{2}\left(\frac{C_{p}(\lambda, \beta)}{\lambda^{3}}-\frac{C_{p \max }}{\lambda_{*}^{3}}\right)$

Because $J, \rho, A, R$, and $\omega^{2}$ are all nonnegative, the sign of $\dot{\omega}$ depends on the sign of the difference within the parentheses. By definition, $C_{p} \leq C_{p_{\max }}$. Thus, when $\lambda>$ $\lambda_{*}, \dot{\omega}$ will be negative, and the rotor will decelerate towards $\lambda=\lambda_{*}$ (since wind is constant in this example). On the other hand, if $\lambda<\lambda_{*}, \dot{\omega}$ will be positive when

$$
C_{p} \geq \frac{C_{p_{\max }}}{\lambda_{*}{ }^{3}} \lambda^{3} \text {. }
$$

The curve

$$
C_{p}=\frac{C_{p_{\max }}}{\lambda_{*}{ }^{3}} \lambda^{3}=F \lambda^{3}
$$

is plotted as the dotted line in Figure 3, and the CART's $C_{p}-\lambda$ curve for a fixed pitch of $-1^{\circ}$ is the solid line. Note that the solid line is simply a two-dimensional slice of Figure 1. Thus, the inequality in Eq. (12) is satisfied for tip speed ratios ranging from about 3.3 to 7.5. As long as the CART has a tip speed ratio of 3.3 or greater, its standard control law (Eq. (1)) will cause its speed to approach the optimum tip speed ratio.

When $\lambda<3.3$, the requirement given by Eq. (12) is no longer satisfied, and $\dot{\omega}<0$. In this case, the rotor speed would actually slow towards zero, and, by Eq. (11), the turbine would remain stopped once $\omega=0$. However, most turbines have other control mechanisms in place to prevent this from occurring (otherwise, the turbines would never start in the first place). The CART, for example, uses blade pitch to change the aerodynamic torque at low tip speed ratios. While the specific tip speed ratio numbers and control mechanisms are different for different turbines, the general idea of the dynamics presented here hold for all variable speed turbines.

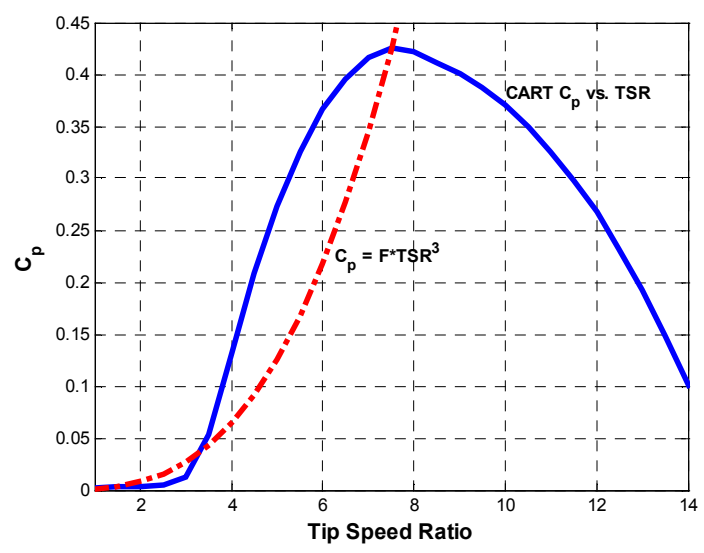

Figure 3: CART $\mathrm{C}_{\mathrm{p}}$ vs. TSR and Cubic TSR

Unfortunately, the modeling tools used to determine the $C_{p}$-TSR-Pitch surface for most wind turbines are not perfectly accurate, and fixed controllers designed based on these modeling tools are generally still sub-optimal. Figure 4 presents a graphical depiction of how sub-optimal performance results in energy loss.

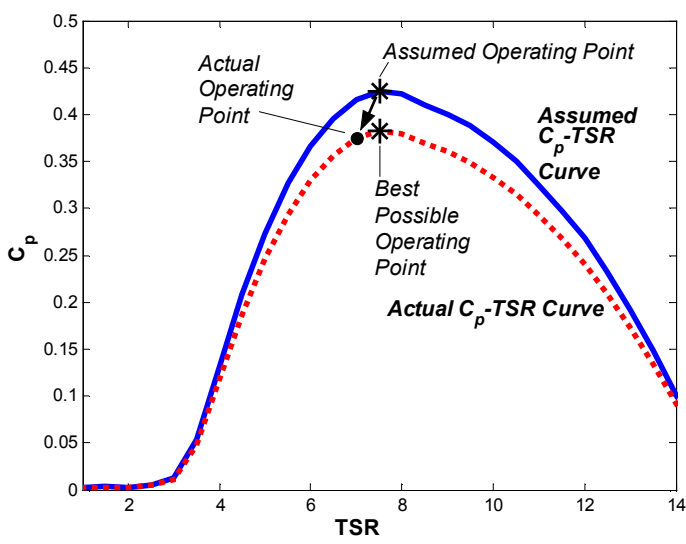

Figure 4: Sub-Optimal Operation Due to Inaccurate C $_{\mathrm{p}}$-TSR Curve

Assume, for example, that the dotted curve in Figure 4 is the actual $C_{p}$ surface and the solid curve is the best guess made by the control engineer based on the modeling tools available. In this case, the control torque $\tau_{c}$ will be designed to drive steady-state operation to the asterisk at the peak of the solid curve. Because $\tau_{c}$ is directly proportional to $C_{p_{\max }}$, as given in Eq. (1)-(2), the net result is that the control torque will 
be higher than warranted by the dotted (real) curve. Then, considering Eq. (7) and for a given aerodynamic torque $\tau_{\text {aero }}$, a higher control torque $\tau_{c}$ will result in a smaller acceleration. All else being equal, the end result of the discrepancy between the two curves will be that the turbine will operate at a slightly lower speed (and thus tip-speed-ratio) than if the solid curve were correct. For this example, steady-state operation will occur at the black circle on the dotted curve, which is lower than the real system's best possible operating point represented by the asterisk on the dotted curve. It should be emphasized that true steady state operation, as described above, occurs only for constant wind, which is never the case.

Even if it could be assumed that the initially chosen gain $k$ was optimal, wind turbine blades will change over time due to issues like bug build-up and blade erosion, causing the same net result as a sub-optimally chosen initial $k$. A study by Fingersh and Carlin [3] shows how sensitive energy loss is to errors in the optimal tip-speed-ratio $\lambda_{*}$ and the maximum power coefficient $C_{p_{\max }}$. The study showed that a very common $5 \%$ error in the optimal tip-speed-ratio $\lambda_{*}$ alone can cause an energy loss of around $1 \%-3 \%$ in region 2 , which is a significant loss in this industry.

The next three sections describe three new methods that can be used to increase energy capture. The first is as simple as reducing the gain $k$ given by Eq. (2) by a small amount, depending on the typical wind turbulence at a given wind turbine.

\section{EFFECTS OF TURBULENCE ON OPTIMAL OPERATING POINT}

The question has arisen as to whether the maximum power capture is actually achieved when the standard control law given by Eq. (1)-(2) is used. In fact, the following simulation results show that using a gain $k$ that is $5 \%-20 \%$ smaller than that given by Eq. (2) actually results in improved power capture, depending on the turbulence in the wind. The reason for this result is the fact that a turbine with high rotor inertia spends much of its region 2 operational time trying to regain the optimum tip speed ratio lost due to wind gusts and lulls; it simply cannot track wind speed perfectly. Because the power in the wind is proportional to the cube of the wind speed, it is more important to track wind gusts than lulls. This concept is explained further throughout this section.

As is shown in Figure 5, a turbine with a very low rotor inertia $\left(J=1000 \mathrm{~kg} \bullet \mathrm{m}^{2}\right)$ has a much different optimal operating point than one like the CART, with $J$ $=388,500 \mathrm{~kg} \bullet \mathrm{m}^{2}$. In Figure 5, "Nominal Power Capture" is the maximum power captured by the turbine with very low rotor inertia at $k / M^{*}=1.0$, all other physical parameters used in simulation being the same. In this plot, three different $100 \mathrm{~Hz}$ sampled wind data sets were used as inputs in simulations. The curves were each created by simulating the CART's behavior 24 times, each simulation lasting one hour and having a different (fixed) value of the torque control gain, $k$. The nominal value, $M^{*}$, is given by

$M^{*}=\frac{1}{2} A R^{3} \frac{C_{p \max }}{\lambda_{*}{ }^{3}}$,

which is simply Eq. (2) with the time varying air density $\rho$ set equal to one for simplicity. For the low rotor inertia $(J=1000)$ case, the power capture is virtually identical no matter which wind is used as input - the lines are indistinguishable on the scale of Figure 5. However, there are noticeable differences in the three plots showing the normal inertia $(J=388,500)$ case. In these simulations, optimum power capture (indicated by the stars) is achieved at anywhere from $89 \%$ to $93 \%$ of the nominal optimal control torque gain. According to these three curves, it is clear that captured power could be increased by $0.5 \%$ simply by reducing the gain $k$ by an average of $10 \%$ below the nominal value. While $0.5 \%$ may not sound like an impressive number, the control modification required is so simple, costing nothing, that there is no question that this change is worthwhile.

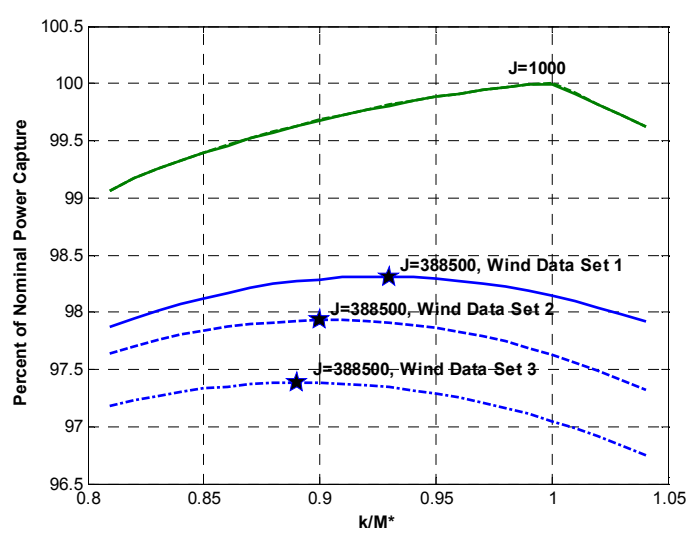

\section{Figure 5: Average Power Capture for Normal and Low Inertia}

Why does the optimum torque gain differ for different wind inputs? Since the three curves from the low inertia simulations lie almost on top of each other and only the high inertia curves differ by wind input, it seems likely that the rotor inertia is the cause of the change in optimum gain from one wind speed to another. A higher inertia will result in slower tracking of the optimal tip speed ratio $\lambda_{*}$ in response to wind gusts and lulls. When characterizing the wind, turbulence intensity is one measure used to describe the amount of "gustiness" in the wind. It is usually defined as the standard deviation of the wind speed divided by 
the mean wind speed over 10 minutes. The following simulations, presented in Figure 6, show that the optimum operating point is closely related to a slightly modified measure of the wind's turbulence intensity. This modified one-hour turbulence intensity uses 60 minutes of data rather than 10 in the mean and standard deviation calculations.

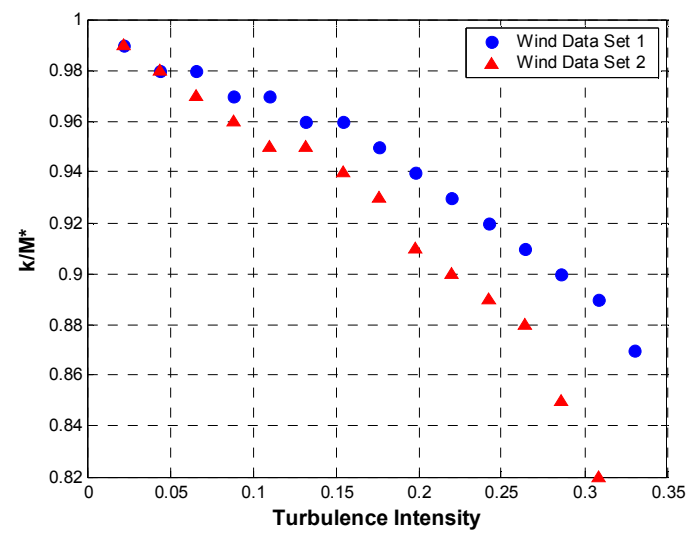

Figure 6: Optimum Torque Gain vs. Turbulence
Intensity

Figure 6 is created in a similar manner to Figure 5. Two of the wind data sets used to create Figure 5 were slightly modified to have the same mean $(7.533 \mathrm{~m} / \mathrm{s})$, and then further scaled to create 15 different standard deviations per wind input, resulting in 15 different onehour turbulence intensities. The simulations were then run for each of these 15 one-hour turbulence intensities per wind data set, holding the mean wind speed constant throughout the experiment. Each simulation was one hour in length and used the normal inertia and other CART parameters. As shown by the "Wind Data Set 2" curve, for high one-hour turbulence intensities, the torque gain resulting in the greatest power capture can be nearly $20 \%$ lower than the nominal value given by Eq. (14).

Similar simulations performed while varying the mean wind speed and holding the one-hour turbulence intensity constant showed that the mean wind speed does not significantly affect the optimum torque control gain. Thus, it can be concluded that it is the standard deviation of the wind speed that forms the correlation between turbulence intensity and optimal torque control gain. The fact that the two curves in Figure 6 do not lie on top of each other indicates that other wind characteristics also play a role. For example, the Richardson number and other factors may also affect the optimum gain, but these are not investigated in this paper.

Why is the optimal torque control gain lower for higher turbulence intensities? Consider this example: imagine that the constant wind has a speed of $10 \mathrm{~m} / \mathrm{s}$, and the CART is operating in steady state with $\omega=$
$3.46 \mathrm{rad} / \mathrm{s}$ (for a tip speed ratio of $\lambda_{*}=7.5$ ). At some time, there is a step change in wind speed to $11 \mathrm{~m} / \mathrm{s}$, which causes the instantaneous tip speed ratio to drop to $\lambda=6.82$. The torque control law will cause the rotor to accelerate towards $\lambda=7.5$, but in the meantime, the power loss is proportional to the cube of the wind speed, or $1331(\mathrm{~m} / \mathrm{s})^{3}$, by Eq. (5). Similarly, if there is a step change in wind speed down to $9 \mathrm{~m} / \mathrm{s}$, the power loss is proportional to $9^{3}=729$. Because of this cubic law relating wind speed and power, it is more important to quickly regain the optimal tip speed ratio following wind gusts than lulls. Since it is safe to assume that, in general, a given wind input will have a similar number of gusts and lulls, using a torque control gain that is slightly smaller than the one given by Eq. (2) is more likely to make Eq. (7) positive, which means the rotor will accelerate more easily in response to a gust.

Turbulence intensity is related to the geological features in a given area, but there are many other atmospheric factors that influence the turbulence at any given time. Thus, for many wind sites, it may not be practical to choose a constant gain reduction factor for the torque controller. The next section describes an alternative approach to the standard control law given by Eq. (1). This approach uses generator torque to assist in the acceleration and deceleration in response to wind gusts.

\section{OPTIMALLY TRACKING ROTOR CONTROL}

Because OTR control was described in depth by Fingersh and Carlin [3], only a brief discussion of its motivation will be provided here before simulation results are presented. The idea for OTR control came from the observation that significant power loss occurred in region 2 as a result of the turbine's inability to accelerate and decelerate quickly in response to wind speed changes. Fingersh and Carlin [3] observed a gap of as much as $10 \%$ between the optimal $C_{p}$ in region 2 and the $C_{p}$ actually achieved by the turbine. In order to achieve a higher $C_{p}$, it is possible to use the generator torque to assist in acceleration or deceleration, thereby causing the turbine to spend more time closer to the optimum tip speed ratio. The authors proposed replacing the standard region 2 control law (Eq. (1)) with the following:

$$
\tau_{c}=k \omega^{2}-G\left(\tau_{\text {aero }}-k \omega^{2}\right)
$$

where $\tau_{\text {aero }}$ can be determined by rearranging Eq. (7). The gain $G$ can be selected to provide a tradeoff between acceleration or deceleration rate and other considerations, such as preventing the turbine from actually drawing power from the grid (motoring).

Figure 7 was created by running 24 one hour simulations for each of three wind inputs for each of the six values of $G$ plotted (i.e., 432 total simulations). The 
results of the three wind inputs, the same as those used to create Figure 5, were averaged before plotting to reduce clutter in Figure 7. The nominal case is $G=0$, which reduces to the standard control law, and $k / M^{*}=$ 1.0. Each curve's maximum is marked with a star. Because of the effects of turbulence intensity, the maximum on the $G=0$ curve is located at $k / M^{*}=0.91$ rather than $k / M^{*}=1.0$. Notice that the maxima for the OTR control cases occur at slightly higher $k / M^{*}$ than the maximum of the nominal standard control law curve; this is because the generator assistance in acceleration and deceleration helps to alleviate the negative effects of the wind gusts and lulls discussed in the previous section.

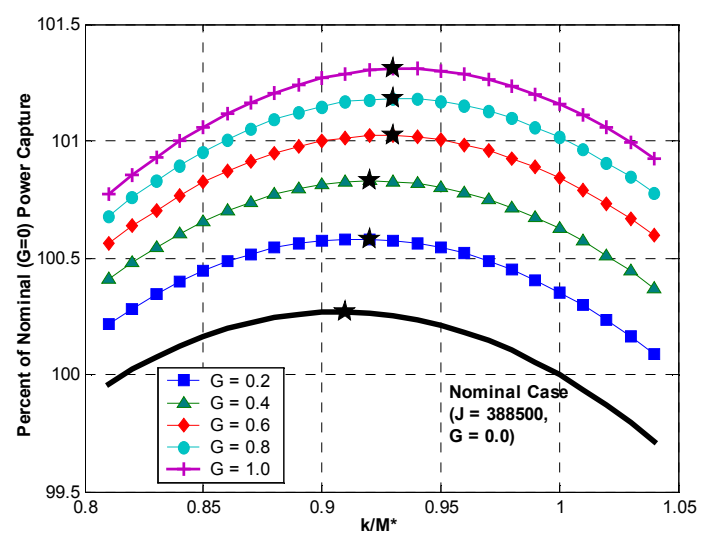

\section{Figure 7: Improved Power Capture with OTR Control}

Even assuming nothing is known about the optimum gain $k$ for a given situation (i.e., the turbulence intensity is unknown, so $k / M^{*}=1$ ), the OTR control algorithm captures more power than the standard region 2 controller. For an aggressive $G=1$, the average increase in power capture over nominal is about $1.2 \%$, as shown by the $G=1$ curve in Figure 7 . More information on OTR control, including results from experiments on the CART, can be found in [4].

The focus of the next section is the implementation of an adaptive controller that moves the steady state operating point to the asterisk on the dotted curve in Figure 4.

\section{ADAPTIVE CONTROL}

A small number of papers have been published regarding adaptive control of wind turbines (including [5]-[11]), but most involve region 3 control, and very few attempts have been made to test these advanced controls on real turbines. One researcher, Bossanyi [8], [9], has performed such tests, studying his adaptive control scheme on a real turbine, but his focus was on pitch control in region 3. Enslin and Van Wyk [10] have tested an adaptive direct speed controller on a small wind turbine, but their direct speed control is very dissimilar to the standard region 2 torque control given by Eq. (1). Bhowmik, Spée, and Enslin [11] have also conducted research that involves direct speed control of a variable speed turbine in order to maintain the optimal tip-speed-ratio, but they used a DC machine set up to simulate a wind turbine rather than an actual turbine in their experiments. In any case, commanding speed explicitly at a high control rate (as in [10], [11]) would cause excessive torques on the drive train of a turbine with a large rotational inertia like the CART.

One solution to the problem of parameter uncertainty in region 2 control is to use a form of Model Reference Adaptive Control (MRAC) [12]. If a suitable model could be found, the gain $k$ in the control torque equation (Eq. (1)) could be adapted in order to drive the turbine to follow the model. In theory, a designer could make an educated initial guess regarding the values of the uncertain parameters and the controller could adapt $k$ towards the point of maximum power capture. Assuming the adaptation process continued throughout the lifetime of the turbine, this controller would be able to track changes in the blade parameters over time.

However, finding such a suitable model for region 2 control is not a simple task. One obvious choice is to measure the wind speed and use it to calculate the wind power available to the rotor. Unfortunately, it is impossible to measure the wind at all points on the rotor plane, and the wind passing through a circle with a radius of 20 meters or more can be very non-uniform. Nevertheless, advances are being made in wind estimation (for example, [13]), and it is possible that the available measurements and estimates may still be accurate enough to allow a MRA controller of this type to operate satisfactorily (i.e., maximize the fraction of power in the wind captured by the turbine).

\section{Gain Adaptation Algorithm}

The research presented here uses a simple, highly intuitive gain adaptation algorithm. In region 2, the adaptive control is very similar to the non-adaptive case presented in Eq. (1)-(2):

$\tau_{c}=\rho M \omega^{2}$.

The adaptive gain $M$ incorporates all of the terms in the non-adaptive torque control gain $k$ except the air density $\rho . \rho$ is kept separate because it is time varying (with changes in the weather) and completely uncontrollable. $M$ is adapted after a certain number $n$ of time steps of operation in region $2 ; n$ is selected to be large enough to average out high frequency wind variations and the slowness of the turbine's response to wind gusts and lulls. Tests on the CART thus far 
indicate that the averaging period defined by $n$ will need to be on the order of tens of minutes to hours.

A simulation was conducted using a rigid body model relating net torque and angular acceleration as in Eq. (7) and using Eq. (16) for the control torque. This simulation was run for 200 seconds with each of 26 different values of the gain $M$, and the turbine's behavior for each of the 26 gain values was averaged to produce Figure 8 . The resulting curve led to the development of the gain adaptation law described next.

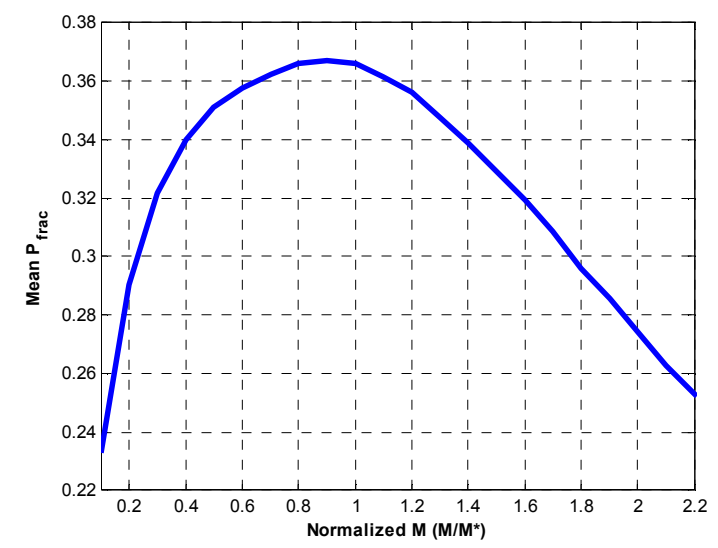

Figure 8: Mean Fractional Power vs. Normalized $M$

The instantaneous fractional power captured is given by

$P_{\text {frac }}=\frac{P_{c a p}}{P_{w y}}$

where

$P_{\text {cap }}=\tau_{c} \omega+J \omega \dot{\omega}$

$P_{w y}=\frac{1}{2} \rho A v^{3} \cos ^{3}(\psi)$.

The first term in $P_{c a p}$ is the generator power and the second is the kinetic power (i.e., the time derivative of the kinetic energy) of the rotor. The yaw error factor $\cos ^{3}(\psi)$ is a necessary component of the available power calculation because a yaw error can significantly reduce the amount of power that the turbine is physically able to capture. While active control of the turbine's yaw position is used to minimize the steadystate yaw error, that yaw control is not part of this research. The reason for incorporating the $\cos ^{3}$ factor into Eq. (19) is to prevent slowness in the yaw control from compromising the adaptive torque control, which would be the case if the gain adaptation law used an inaccurate measure of available wind power. Though $\cos ^{3}$ is only an approximation of the complex aerodynamic effects of yaw error, it is very close (within a few percent up to a $20^{\circ}$ yaw error) to the actual power reduction caused by yaw error, as shown in Figure 9. Figure 9 plots the fraction of available power for a given yaw error for two cases: the $\cos ^{3}$ approximation and real data collected from NREL's Unsteady Aerodynamics experiment [14]. It should be noted that the Unsteady Aerodynamics experimental data, collected in a wind tunnel, gives virtually identical results to an aerodynamic simulation run with the CART's parameters using the modeling tool SymDyn [15]; thus, the SymDyn curve has been omitted from the plot.

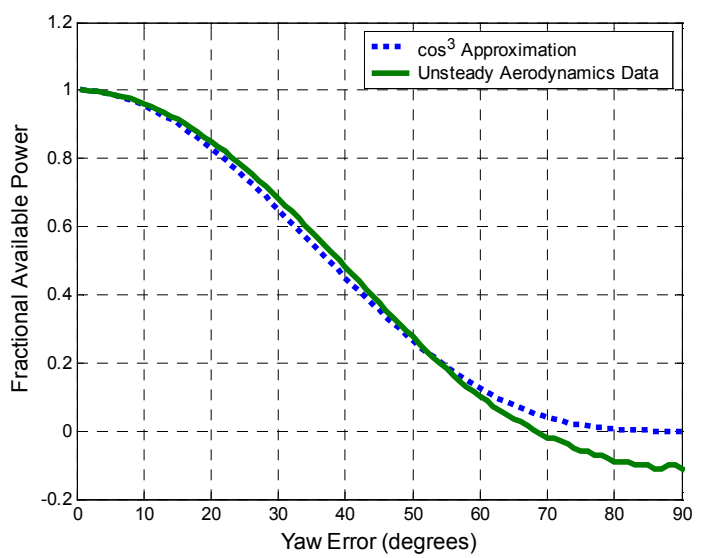

\section{Figure 9: Decrease in Available Power vs. Yaw Error}

Given that a properly operating turbine will have zero mean yaw error and that fluctuations in instantaneous wind direction (and thus yaw error) will be very similar from one adaptation period to the next, these small percentages will cause no more than a very small fraction of a percent difference in the calculation of $P_{w y}$ for any two adaptation periods. Thus, using the $\cos ^{3}$ approximation to the yaw error factor is not expected to cause problems for the gain adaptation law.

The only difference between $P_{\text {wind }}$, defined in Eq. (5), and $P_{w y}$ is the $\cos ^{3}(\psi)$ factor. Whenever $\psi$ is zero, as in the simulation producing Figure 8 , the two definitions become identical. The reason that $P_{c a p}$ is used in the calculation of $P_{\text {frac }}$ rather than the turbine power $P$ given in Eq. (6) is that the sensor requirements are more reasonable, given the instrumentation normally available on an industrial turbine. The two definitions of the turbine's captured power are closely related, differing only by the inevitable mechanical losses in the turbine's gearbox that make $P_{c a p}<P$ by a small amount. Given that fact and the fact that $P_{\text {wind }} \geq$ $P_{w y}$, it is impossible to state definitively whether $P_{\text {frac }}<$ $C_{p}$ (Eq. (4)) or vice versa at any given instant. However, it can be stated that they are closely related.

The adaptive controller begins by changing $M$ by some value $\Delta M$. At the end of the adaptation period, the controller evaluates the turbine's performance, averaging the captured power and the wind power and computing the ratio of the averages. If the fraction of the averaged powers $P_{\text {frac }}$ is greater than the mean 
fractional power in the preceding adaptation period, the controller selects a new $\Delta M$ of the same sign as the previous one. This process continues in the same manner until the fractional power is less than that of the preceding adaptation period. At that point, the new $\Delta M$ is calculated to have the opposite sign of the previous $\Delta M$. Eventually, $M$ should converge toward $M^{*}$, the optimal gain.

The mathematical equations implementing this gain adaptation are

$$
\begin{aligned}
& M(k)=M(k-n)+\Delta M(k), \\
& \Delta M(k)=\frac{\left.\operatorname{sign}[\Delta M(k-n)] \operatorname{sign}\left[\Delta P_{\text {favg }}(k)\right] \Delta P_{\text {favg }}(k)\right|^{1 / 2}}{K_{\Delta M}}, \\
& \Delta P_{\text {favg }}(k)=P_{\text {favg }}(k)-P_{\text {favg }}(k-n),
\end{aligned}
$$

and

$$
P_{\text {favg }}(k)=\frac{\frac{1}{n} \sum_{i=1}^{n} P_{c a p}(k-n+i)}{\frac{1}{n} \sum_{i=1}^{n} P_{w y}(k-n+i)} .
$$

In Eq. (21), the $\left|\Delta P_{\text {favg }}(k)\right|^{1 / 2}$ factor is an indicator of the closeness of $M$ to the optimal operating point. When $M$ is such that operation is near the peak of the curve shown in Figure 8, a given $\Delta M$ will cause a smaller $\left|\Delta P_{\text {favg }}\right|$ due to the flatter nature of the curve near its peak. Thus, $\Delta M$ will get smaller and smaller as the optimal point is approached. The exponent $1 / 2$ was chosen based on empirical results in simulation.

It may seem that this simple adaptation scheme is rather slow. However, in the decades-long life of a wind turbine, several hours, days, or even weeks spent identifying the initial optimal operating point are not significant in terms of power lost or time wasted. Additionally, the aerodynamic changes that occur to all turbine blades typically take place on an even slower time scale than that of the adaptive controller. Thus, an adaptation period on the order of hours should not be a significant problem for a commercial turbine designer.

Although this gain adaptation scheme has not been theoretically proven to work (i.e., to maximize the fractional power captured by the turbine), simulations have demonstrated the desired behavior, and real turbine experiments have demonstrated an increase in power capture over the standard control scheme. While stability of the gain adaptation law has also not been proven theoretically, both simulations and experimental data have indicated that the system is stable. Further, there are many safety mechanisms protecting the turbine independent of the control technique described in this paper, and any system that changes over the long time intervals typical of this adaptation scheme is unlikely to cause catastrophic damage due to instability. At this point, the controller's intuitive nature and ease of implementation far outweigh its drawbacks.
One main difference between the adaptive control described in this research and some of the adaptive controllers developed in previous research is which parameters are assumed to be unknown. In this research, the controller attempts to have the turbine power track the wind power but assumes $C_{p_{\max }}$ and $\lambda_{*}$ are unknown. In contrast, previous adaptive controllers such as those presented in [5]-[6] force the turbine to track a desired rotor speed in region 2. However, in order to develop a model for desired rotor speed, it is necessary to have some knowledge of the $C_{p}$ surface, particularly $C_{p_{\max }}$ and $\lambda_{*}$. As discussed previously in this research, the fact that those two parameters are not well known is a major source of energy loss in region 2. An additional difference among the various adaptive controllers is the lengthy averaging period used in this research, compared to the very short time periods used in previous adaptive controllers. These short time periods may cause the adaptive controllers to have trouble distinguishing between performance changes caused by changes in the controller and those caused by wind gusts and lulls.

\section{$\underline{\text { Simulations }}$}

Numerous simulations have been run to demonstrate that the controller results in the desired turbine behavior. Like the simulation used in producing Figure 8, these were performed using a simple, single-integrator model (Eq. (7)) of a horizontal axis wind turbine (HAWT) with the same characteristics as the CART. The simulations were done using Matlab's ${ }^{\circledR}$ modeling software, Simulink ${ }^{\circledR}$. A simplified Simulink model is shown in Figure 10.

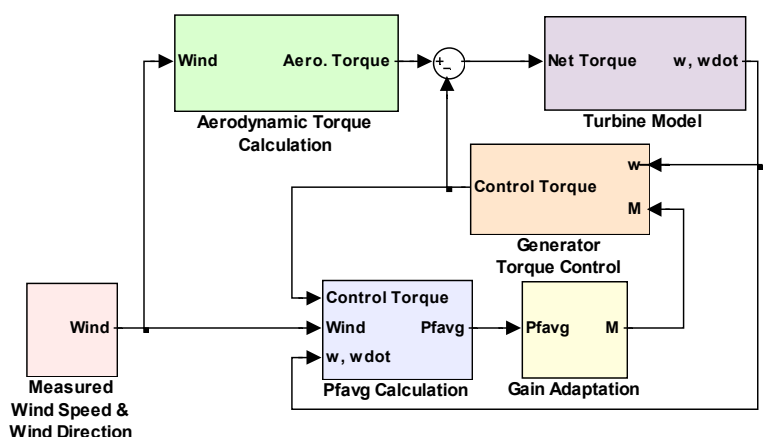

Figure 10: Simplified Simulink Model of CART and Adaptive Controller

Equations (20)-(22) are implemented in the Gain Adaptation block. Similarly, Eq. (16) is computed in the Generator Torque Control block. The Aerodynamic Torque Calculation block implements Eq. (8), using a surface similar to the one in Figure 1 to determine $C_{q}$, given the relationship between $C_{p}$ and $C_{q}$ as described in Eq. (9). The Turbine Model block integrates Eq. (7) 
to obtain the angular velocity $\omega$. Finally, the Pfavg Calculation block performs Eq. (18), (19), and (23).

Some simulations have used measured wind data, while others have used simulated wind data. Where possible, the Simulink model uses the same control as would be implemented on the CART. One of the simulation outputs, which used a constant wind input, is plotted in Figure 11, with simulation parameters listed in Table 1.
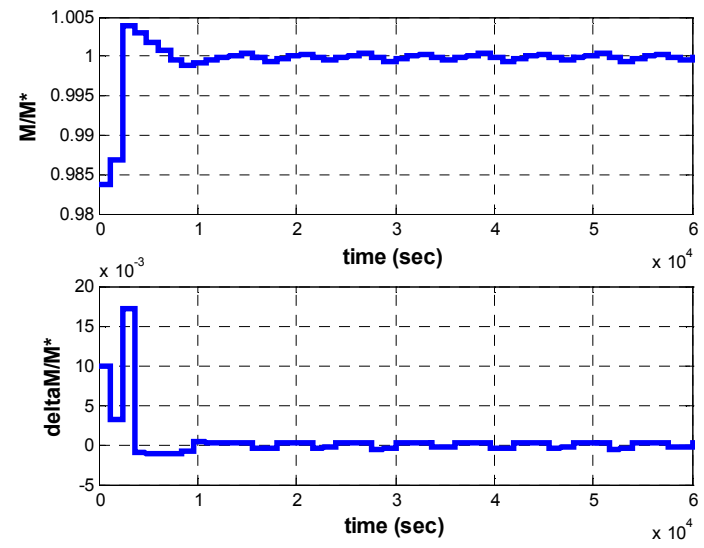

Figure 11: Simulation Results with Constant Wind Input

Table 1: Simulation Parameters

\begin{tabular}{|c|c|}
\hline Parameter & Value \\
\hline$J$ & $388,500 \mathrm{~kg} \bullet \mathrm{m}^{2}$ \\
\hline$R$ & $21.65 \mathrm{~m}$ \\
\hline$M^{*}$ & $174.48^{\dagger} \mathrm{m}^{5} / \mathrm{rad}^{3}$ \\
\hline$K_{\Delta M}$ & $10^{-3} \mathrm{rad}^{3} / \mathrm{m}^{5}$ \\
\hline$\rho$ & $1.0 \mathrm{~kg} / \mathrm{m}^{3}$ \\
\hline$f_{s}$ & $100 \mathrm{~Hz}$ \\
\hline
\end{tabular}

Figure 11 uses an adaptation period of 20 minutes, meaning that $n$, the number of steps between adaptations, is equal to 120,000 . Clearly, the bulk of the changes in this particular case occur in the first dozen adaptation periods. After that, the value of $M$ oscillates near the expected value, $M^{*}$. Because the adaptation scheme uses only the most recent past value in addition to the current value of the adaptation parameters, these oscillations are not unexpected. Future work will investigate incorporating additional past values to reduce the oscillations. In Figure 11, both $M$ and $\Delta M$ are normalized by $M^{*}$, which, according to Figure 1 is nominally the ideal value. Because the wind is constant (turbulence intensity $=0$ ), note that optimal behavior occurs at $M=M^{*}$. However, that may not be true for the real turbine, for which $M^{*}$ is

\footnotetext{
${ }^{\dagger}$ This value is referenced to the High Speed Shaft. On the rotor side of the gearbox, $M^{*}=7530.41 \mathrm{~m}^{5} / \mathrm{rad}^{3}$.
}

not precisely known, and is not true for simulations using real (turbulent) wind data as an input, as shown in Figure 12.
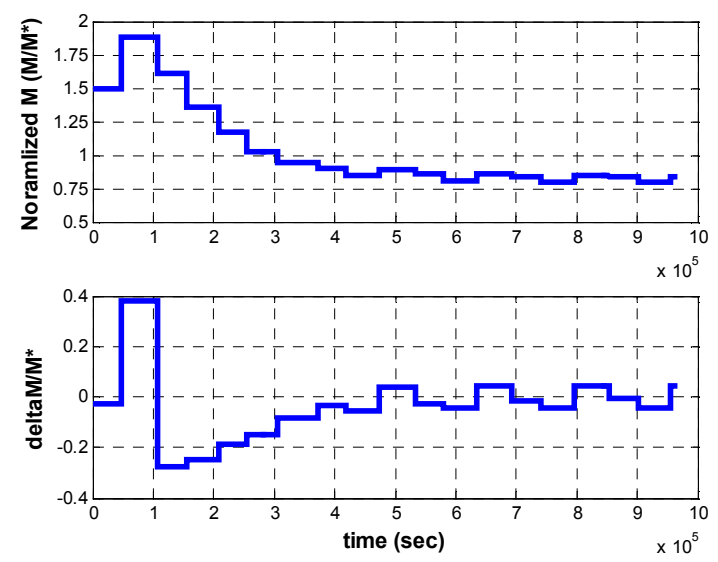

Figure 12: Simulation Results with Real Wind Data
as Input

The turbulence at the NWTC during the winter wind season tends to be higher than the average at a typical wind site; thus, it is expected that using measured wind speeds will result in $M$ converging to some value approximately $20 \%$ lower than $M^{*}$. This turbulence effect can be seen in the top plot of Figure 12. Further, it is clear that convergence under real wind input does not occur as quickly as it does with constant wind, though it seems that the system is stable in some sense, since the normalized $\Delta M$ is oscillating around zero. It is also important to note that Figure 12 required the use of a much larger $n$ than Figure 11 due to the timevarying wind. In the case of Figure 12, $n=4,680,000$, which translates to 13 hours.

\section{Real Turbine Experiments}

The CART is an invaluable tool for determining the benefit of this new adaptive controller to the turbine industry. Issues that may not arise in simulation must be solved before any new controller can be trusted by the industry. For example, in the first significant experiment on the CART, the nacelle anemometer was used in the calculation of $P_{w y}$ (Eq. (19)). This anemometer would be available on a commercial wind turbine. Unfortunately, it seems that simply using the measured wind speed on the nacelle results in improper adaptation. Although the aerodynamics behind the rotor and around the nacelle are very complicated while the turbine is operating, it is believed that the major error in the nacelle anemometer measurements is due to the well known axial induction factor. The effect of the axial induction factor is that, for a given upwind wind speed, a faster spinning rotor (i.e., higher tip speed ratio) results in slower wind downwind of the rotor. Thus, the measured $P_{w y}$ actually appears lower than the 
true available wind power, and the value of $P_{\text {frac }}$ given by Eq. (17) is misleadingly larger.

Figure 13 shows data from nearly all of the adaptations that occurred during the four months between the initial implementation and the end of the wind season.

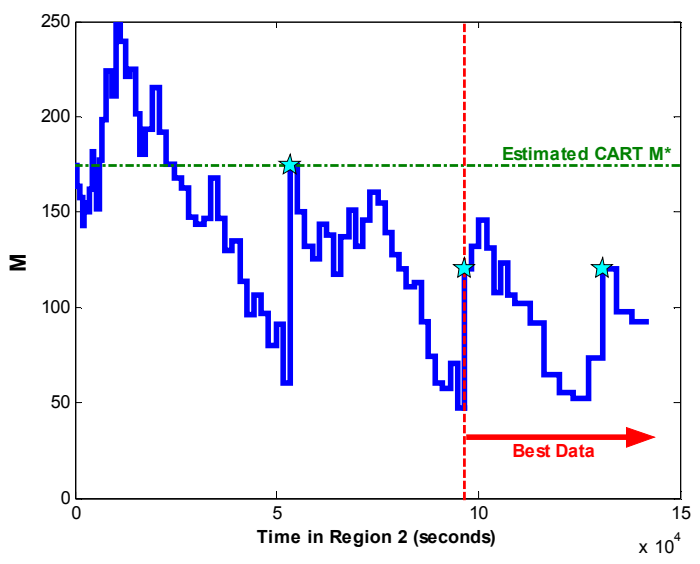

Figure 13: Adaptations of $M$ on the CART

The adaptation period used to collect the data plotted in Figure 13 is 10 minutes for the first 11 adaptations, 20 minutes for the next nine adaptations, 30 minutes for the following 51 adaptations, and 60 minutes $(n=360,000)$ for the remaining nine. During the time covered by Figure 13, there were numerous changes made to the adaptive controller as minor errors were discovered; only to the right of the vertical dotted line is the algorithm implemented exactly as described in Eq. (20)-(23). In addition, there were several problems with sensors on the CART discovered. For example, the drop in $M$ between about 550 and 900 minutes is partly a result of an erroneous wind direction sensor. As a result of changes in the control algorithm and sensor failures, the value of $M$ was re-set three times during the four months; these times are marked by the stars along the plot. Finally, it is evident that even a 30-minute adaptation period is too short to result in convergence of $M$, which is consistent with the 13hour adaptation period used to create Figure 12. Unfortunately, the wind resources did not last long enough to extend the data collection beyond the nine adaptations with 60-minute adaptation periods. Finally, in the interest of clarity, the time scale in Figure 13 reflects only the time spent operating in region 2 .

The data collected on the CART is, unfortunately, insufficient for showing that the proposed adaptive controller does or does not work in terms of whether or not $M$ converges to an optimum value. However, it is still possible to compare this controller with the standard non-adaptive controller (Eq. (1)) in terms of power capture. In fact, based on data analysis, it has been determined that the gain $k$ used in the standard variable speed region 2 CART controller may have been close to $100 \%$ higher than the true optimum value for the turbine, resulting in significant power loss. Figure 14 provides a plot comparing the mean low speed shaft power vs. mean wind speed for the standard controller and the adaptive controller. The standard controller data is actually a random, representative sampling of the data collected using the standard controller and presented in [4], since using all of that data makes the plot very crowded and difficult to read. The adaptive controller data includes those data sets for which $M<99.5$. For mean wind speeds below about 13 $\mathrm{m} / \mathrm{s}$, the power curve follows the expected cubic relationship between wind speed and power. Above that wind speed, the turbine frequently operates in region 3, and the power limiting control algorithm (not discussed in this research) takes over, which causes the flattening of the curve.

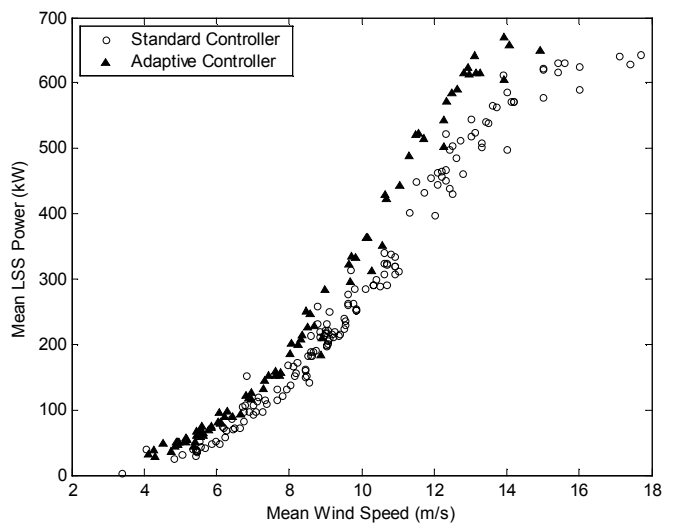

Figure 14: 10-Minute Averages of Low Speed Shaft Power vs. Wind Speed for Standard and Adaptive Control

As is clearly evident in Figure 14, there is some overlap between the controllers. However, there is a distinct curve of adaptive control data lying above the standard control data. This curve shows that, for the values of $M$ that are less than $43 \%$ of the CART's predicted $M^{*}$, more power is captured. In fact, analysis of the CART's constant speed controller data in [4] has shown that the optimum tip speed ratio $\lambda_{*}$ for the CART is probably closer to 9.5 than the predicted 7.5 , and the $C_{p_{\max }}$ is about 0.45 rather than 0.425 . Given the equation for $M^{*}$ (Eq. (14)), these errors result in a torque control gain about $92 \%$ higher than the optimum gain for maximum power capture.

\section{CONCLUDING REMARKS}

An analysis of the standard region 2 control scheme $\left(\tau_{c}=k \omega^{2}\right)$ for variable speed wind turbines reveals some of its shortcomings, specifically those 
caused by the turbulence in the wind and the difficulty in determining the gain $k$. Three new control ideas were proposed to address these shortcomings. First, a very simple scheme reduced $k$ by $5 \%-20 \%$ in order to better capture the power available in wind gusts. This change can result in a $0.5 \%$ increase in power capture with virtually no cost, and can be implemented on any existing turbine that uses the standard torque controller in region 2. Next, an optimally tracking rotor (OTR) control algorithm was tested in simulation. The OTR controller uses generator torque to assist in acceleration and deceleration of the rotor in response to wind gusts and lulls. It can result in a $1 \%$ or more increase in power capture, depending on various parameters. Finally, a model reference adaptive control scheme was been developed and tested both in simulation and on the CART. This controller uses information on power available in the wind in an attempt to maximize power captured by the turbine. The main advantage of the adaptive controller is the potential for increased longterm energy capture over a fixed-gain controller by eliminating the problem of parameter uncertainty in $k$. The adaptive controller differs from the simple reduction in $k$ described above because it does not depend on the initial determination of $k$ that is near the true value.

\section{ACKNOWLEDGEMENTS}

This work was funded by the U. S. Department of Energy (through the National Renewable Energy Laboratory under contract number DE-AC3699G010337), the University of Colorado at Boulder, and the American Society for Engineering Education.

\section{REFERENCES}

[1] Walker, S. N. and Wilson, R. E., 1976, Performance Analysis Program for Propeller Type Wind Turbines, Oregon State University, Corvallis, Oregon.

[2] Burton, T., Sharpe, D., Jenkins, N., and Bossanyi, E., 2001, Wind Energy Handbook, John Wiley \& Sons, New York.

[3] Fingersh, L. J. and Carlin, P. W., 1998, "Results from the NREL Variable-Speed Test Bed," Proceedings of the $17^{\text {th }}$ ASME Wind Energy Symposium, Reno, NV, pp. 233-237.

[4] Fingersh, L. J. and Johnson, K. E., 2004, "Baseline Results and Future Plans for the NREL Controls Advanced Research Turbine." Submitted for publication in the Proceedings of the $23^{\text {rd }}$ ASME Wind Energy Symposium.

[5] Freeman, J. B. and Balas, M. J., 1999, "An Investigation of Variable Speed Horizontal-Axis Wind Turbines Using Direct Model-Reference Adaptive
Control," Proceedings of the $18^{\text {th }}$ ASME Wind Energy Symposium, Reno, NV, pp. 66-76.

[6] Song, Y. D., Dhinakaran, B., and Bao, X.Y., 2000, "Variable Speed Control of Wind Turbines Using Nonlinear and Adaptive Algorithms," Journal of Wind Engineering and Industrial Aerodynamics, 85, pp. 293308.

[7] Dambrosio, L. and Fortunato, B., 1999, “One-StepAhead Adaptive Control of a Wind-Driven, Synchronous Generator System," Energy, 24, pp. 9-20.

[8] Bossanyi, E. A., 1987, "Adaptive Pitch Control for a $250 \mathrm{~kW}$ Wind Turbine," Proceedings of the British Wind Energy Conference, pp. 85-92.

[9] Bossanyi, E. A., 1989, "Adaptive Control of the MS2 Wind Turbine. Practical Results," Wind Engineering, 13, No. 5, pp. 259-273.

[10] Enslin, J. H. R. and Van Wyk, J. D., 1992, “A Study of a Wind Power Converter with MicroComputer Based Maximal Power Control Utilising an Over-Synchronous Electronic Scherbius Cascade," Renewable Energy, 2, pp. 551-562.

[11]Bhowmik, S., Spée, R., and Enslin, J. H. R, 1999, "Performance Optimization for Doubly-Fed Wind Power Generation Systems," IEEE Transactions on Industry Applications, 35, No. 4, pp. 949-958.

[12] Narendra, K. and Annaswamy, A., 1989, Stable Adaptive Systems, Prentice-Hall, Englewood Cliffs, NJ. [13] Balas, M. J., Lee, Y. J., and Kendall, L., 1998, "Disturbance Tracking Control Theory with Application to Horizontal Axis Wind Turbines," Proceedings of the $17^{\text {th }}$ ASME Wind Energy Symposium, Reno, NV, pp. 95-99.

[14]Fingersh, L. J., Simms, D., Hand, M., Jager, D., Cotrell, J., Robinson, M., Schreck, S., and Larwood, S., 2001, "Wind Tunnel Testing of NREL's Unsteady Aerodynamics Experiment," Proceedings of the $20^{\text {th }}$ ASME Wind Energy Symposium, Reno, NV, pp. 194200.

[15] Stol, K. A., and Bir, G. S. "SymDyn User's Guide," NREL/EL-500-33845. National Renewable Energy Laboratory, Golden, Colorado, 2003. 


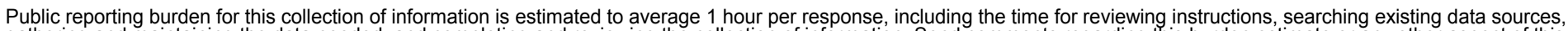

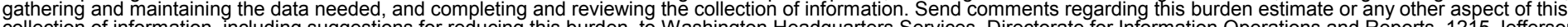
Davis Highway, Suite 1204, Arlington, VA 22202-4302, and to the Office of Management and Budget, Paperwork Reduction Project (0704-0188), Washington, DC 20503.

\begin{tabular}{|l|l|l|}
\hline 1. AGENCY USE ONLY (Leave blank) & $\begin{array}{l}\text { 2. REPORT DATE } \\
\text { November 2003 }\end{array}$ & $\begin{array}{l}\text { 3. REPORT TYPE AND DATES COVERED } \\
\text { Conference Paper }\end{array}$ \\
\hline
\end{tabular}

4. TITLE AND SUBTITLE Methods for Increasing Region 2 Power Capture on a Variable Speed HAWT: Preprint

5. FUNDING NUMBERS WER3-1930

6. AUTHOR(S)

K.E. Johnson, L.J. Fingersh, M.J. Balas, and L.Y. Pao

7. PERFORMING ORGANIZATION NAME(S) AND ADDRESS(ES)

National Renewable Energy Laboratory

1617 Cole Blvd.

Golden, CO 80401-3393

9. SPONSORING/MONITORING AGENCY NAME(S) AND ADDRESS(ES)

8. PERFORMING ORGANIZATION REPORT NUMBER

NREL/CP-500-34979

10. SPONSORING/MONITORING AGENCY REPORT NUMBER

11. SUPPLEMENTARY NOTES

12a. DISTRIBUTION/AVAILABILITY STATEMENT

National Technical Information Service

12b. DISTRIBUTION CODE

U.S. Department of Commerce

5285 Port Royal Road

Springfield, VA 22161

13. ABSTRACT (Maximum 200 words)

The standard region 2 control scheme for a variable speed wind turbine, $\tau_{c}=k \omega^{2}$, has several shortcomings that can result in significant power loss. The first of these is that there is no accurate way to determine the gain $k$; modeling programs are not accurate enough to represent all of the complex aerodynamics, and these aerodynamics change over time. Furthermore, it is not certain whether the value of $k$ used in the standard control even provides for the maximum energy capture under real-world turbulent conditions. New control ideas are introduced to address these issues. First, it is shown in simulation that using smaller values of $k$ than the standard can result in increased power capture. Second, an optimally tracking rotor control scheme improves upon the standard scheme by assisting the rotor speed in tracking wind speed fluctuations more rapidly. Finally, an adpative control scheme is proposed that allows for maximum power capture despite parameter uncertainty.

14. SUBJECT TERMS wind turbine; variable speed wind turbine; wind turbine control system; renewable energy

15. NUMBER OF PAGES

17. SECURITY CLASSIFICATION OF REPORT Unclassified

NSN 7540-01-280-5500
18. SECURITY CLASSIFICATION OF THIS PAGE Unclassified
19. SECURITY CLASSIFICATION OF ABSTRACT Unclassified
16. PRICE CODE

20. LIMITATION OF ABSTRACT

UL 